\title{
Eosinophilic inflammation in cough variant asthma
}

\author{
A. Niimi, R. Amitani, K. Suzuki, E. Tanaka, T. Murayama, F. Kuze
}

Eosinophilic inflammation in cough variant asthma. A. Niimi, R. Amitani, K. Suzuki, E. Tanaka, T. Murayama, F. Kuze. CERS Journals Ltd 1998.

ABSTRACT: Eosinophils are considered to play a central pathogenetic role in asthma. We previously reported that sputum eosinophilia was observed in patients with cough variant asthma (CVA), as well as in "classic" asthma with wheezing. This study was undertaken to further investigate the involvement of eosinophils in CVA.

The serum eosinophil cationic protein (ECP) level, the percentage of eosinophils in bronchoalveolar lavage (BAL) fluid, and the number of eosinophils in bronchial biopsy specimen were examined in 14 patients with CVA, 21 with classic asthma, and in seven healthy controls. For the two asthmatic groups, the clinical severity was classified with scores of 1-3.

Pulmonary function and bronchial responsiveness were not significantly different between the patients with classic asthma and those with CVA. BAL, tissue eosinophil and serum ECP were all significantly increased in both classic asthma and CVA when compared with the controls but were not different between classic asthma and CVA. In both groups of asthmatics, the clinical severity significantly correlated with serum ECP and tissue eosinophils.

In conclusion, eosinophilic inflammation is involved in cough variant asthma as well as in classic asthma. Anti-inflammatory treatment may be essential in patients with CVA, as in those with classic asthma.

Eur Respir J 1998; 11: 1064-1069.
Dept of Infection and Inflammation, Chest Disease Research Institute, Kyoto University, Kyoto, Japan

Correspondence: A. Niimi, Dept of Infection and Inflammation, Chest Disease Research Institute, Kyoto University, 53 Kawahara-cho, Shogoin, Sakyo-ku, Kyoto 606, Japan

Fax: 81757514643

Keywords: Bronchial biopsy, bronchoalveolar lavage, cough variant asthma, eosinophils, eosinophil cationic protein, inflammation

Received: August 191997

Accepted after revision February 161998

This study was supported in part by a Grant-in-Aid for Scientific Research from the Ministry of Education, Science, and Culture (07770421) of the Japanese government.
Cough is commonly associated with wheezing and dyspnoea in symptomatic asthmatics. Wheezing is generally considered to be the sine qua non of asthma. However, it has been recognized that cough may be the sole manifestation of the disease. In 1979, CORRAO et al. [1] reported on six subjects complaining of chronic persistent cough without wheezing or dyspnoea. The subjects had no past history of asthma. They had normal baseline spirometry but bronchial hyperresponsiveness, as demonstrated with methacholine. Coughing soon disappeared after starting either oral bronchodilators, theophylline or terbutaline, but recurred when they were stopped. The authors regarded these subjects as having a variant form of asthma, which was named cough variant asthma (CVA). Several reports on CVA [2-9] followed that of CORRA0 et al. [1], and the condition is now recognized as a common cause of chronic cough $[4,5]$.

Recent research has clarified that asthma is a chronic inflammatory airway disease, in which eosinophils play a central role: granular constituents of eosinophils are cytotoxic and cause desquamation and destruction of bronchial epithelium [10], which may lead to bronchial hyperresponsiveness [11]; lipid mediators secreted from eosinophils, such as leukotrienes $\mathrm{C}_{4}, \mathrm{D}_{4}$, and $\mathrm{E}_{4}$, and platelet activating factor, can induce bronchoconstriction, vascular permeability, and bronchial hyperresponsiveness [10]. Clinical studies in asthmatic patients have almost always demonstrated that eosinophils are increased in number and are activated in the peripheral blood, sputum, bronchoalveolar lavage (BAL) fluid, and bronchial mucosa [11-14]. Furthermore, many, although not all, studies have shown that the intensity of eosinophilic inflammation can correlate with the clinical severity of the disease [14], bronchial responsiveness $[11,12]$ or degree of airflow obstruction [12, 14].

These studies were performed in "classic" asthmatics who complained of wheezing. Only two studies, to our knowledge, have examined the relationship between CVA and inflammation $[6,15]$. We previously performed a sputum study [6] in a small number of patients with CVA, to see whether eosinophils are increased in their sputum, as reported in classic asthma [13]. Five out of 6 patients showed a marked increase of eosinophils in sputum (more than $80 \%$ of the nucleated cells). The mean \pm SD of the percentage of eosinophils was $74.5 \pm 31.4 \%$ and was not significantly different from that of eight patients with classic asthma $(80.6 \pm 22.3 \%)$. Recently, CARNEY et al. [15] have reported that an increase of eosinophil count $(>3.2 \%)$ in induced sputum was observed in three out of six patients with chronic cough and bronchial hyperresponsiveness, who might be given a diagnosis of CVA [1]. The prevalence of eosinophil count elevation in the coughers was significantly higher than that in normal controls ( 0 out of 16 subjects). These reports suggest a role of eosinophils in the pathogenesis of CVA. In the present study, we measured the serum level of eosinophil cationic protein (ECP, one of the eosinophil granule proteins), and performed BAL as well as bronchial biopsies in a larger number of patients with CVA, and in patients with classic asthma and healthy control subjects, to further investigate the involvement of eosinophilic inflammation in CVA. 


\section{Materials and methods}

\section{Subjects}

Fourteen patients with CVA, 21 patients with classic asthma, and seven healthy subjects were studied in a cross-sectional manner.

The patients with CVA were referred to our clinic for chronic cough persisting for longer than 8 weeks but without wheezing or dyspnoea. They had no past history of asthma or other respiratory diseases. Wheeze or rhonchi were not audible on chest auscultation even at forced expiration. The subjects all had bronchial hyperresponsiveness to inhaled methacholine (see below for method). Bronchodilators (inhaled $\beta_{2}$-agonists and/or oral sustainedrelease theophyllines) were effective against their coughs. No other apparent causes of cough were present [4], they did not have any signs or symptoms of postnasal drip or gastro-oesophageal reflux, had not been taking angiotensin-converting enzyme inhibitors, and had normal chest radiograph results. Only one patient with CVA included in this study was also included in each of our previous reports $[6,7]$.

The patients with classic asthma had a history of episodic dyspnoea, wheezing and cough. They had at least $15 \%$ reversibility of forced expiratory volume in one second (FEV1) after inhalation of $200 \mu \mathrm{g}$ of salbutamol and/ or bronchial hyperresponsiveness to methacholine.

The control subjects had no past history of asthma or other respiratory diseases and had no current respiratory symptoms.

Each patient with CVA or classic asthma had been treated with inhaled $\beta_{2}$-agonists (used as needed) and/or oral sustained-release theophyllines (taken twice daily). Furthermore, some of the patients had been inhaling beclomethasone dipropionate $\left(400-800 \mu \mathrm{g} \cdot \mathrm{day}^{-1}\right)$ (table 1). Treatment with $\beta_{2}$-agonists was withheld for $8 \mathrm{~h}$ prior to the tests of bronchial responsiveness or pulmonary function, but not blood sampling or bronchoscopy, since $\beta_{2}$ agonists are considered unlikely to affect the eosinophils [14]. Treatment with theophylline and beclomethasone was withheld for $48 \mathrm{~h}$ and 1 month, respectively, prior to all these examinations. None of the studied subjects had ever taken systemic corticosteroids, cromoglycate or other anti-allergic agents, had smoked within the previous 2 yrs, or had respiratory infections within the previous 8 weeks.

The study was approved by the ethics committee of our institute, and written informed consent was obtained from all participating subjects.

\section{Serum ECP measurement}

Blood samples for ECP measurement were taken between 08:00 and 09:00 h. Since it has been suggested that serum ECP levels can be influenced by the coagulation process and by in vitro handling of the samples, all tests for ECP measurements were performed in the same run to avoid interassay variations, according to the method of Venge [16]. Briefly, $4 \mathrm{~mL}$ of blood were collected into a silicone-containing tube (SST tube) (Becton Dickinson, Mountain View, CA, USA). The blood samples were stored for $60 \pm 5 \mathrm{~min}$ at $25^{\circ} \mathrm{C}$ and subsequently centrifuged at $1,300 \times \mathrm{g}$ at $4^{\circ} \mathrm{C}$ for $10 \mathrm{~min}$. The sera were stored at $-20^{\circ} \mathrm{C}$ until measurement of ECP concentration by a radioimmunosorbent assay (RIA) using an ECP radioimmunoassay kit (Pharmacia Diagnostics, Uppsala, Sweden). The detection limit of this kit is $2.0 \mu \mathrm{g} \cdot \mathrm{L}^{-1}$.

\section{Bronchoscopy, BAL and bronchial biopsy}

Fibreoptic bronchoscopy was performed on the afternoon of the day of blood sampling. Intramuscular atropine hydroxyzine and inhaled salbutamol $(200 \mu \mathrm{g})$ were administered $30 \mathrm{~min}$ before the procedure. Topical anaesthesia

Table 1. - Background of the subjects

\begin{tabular}{|c|c|c|c|}
\hline & Classic asthma & $\begin{array}{l}\text { Cough variant } \\
\text { asthma }\end{array}$ & Control \\
\hline Total number of subjects & 21 & 14 & 7 \\
\hline Age yrs & $46(20-64)$ & $49.5(24-68)$ & $54(23-67)$ \\
\hline Male: Female & $11: 11$ & $6: 8$ & $3: 4$ \\
\hline Duration of the disease yrs & $1.6(0.1-57.0)$ & $1.0(0.2-15.0)$ & - \\
\hline Exsmoker:lifetime nonsmoker & $7: 14$ & $3: 11$ & $1: 6$ \\
\hline Total $\mathrm{IgE}^{*} \mathrm{IU} \cdot \mathrm{mL}^{-1}$ & $237(5-3196)$ & $96(7-905)$ & Not tested \\
\hline Atopic ${ }^{\dagger}$ nonatopic & $15: 6$ & $6: 8$ & $2: 5$ \\
\hline \multicolumn{4}{|l|}{ Medications used before study } \\
\hline$\beta_{2}^{\ddagger}$ & 2 & 4 & - \\
\hline Theo & 4 & 0 & - \\
\hline$\beta_{2}+$ Theo & 10 & 9 & - \\
\hline$\beta_{2}+$ Theo+BDP\# & 5 & 1 & - \\
\hline Clinical severity mild:moderate:severe ${ }^{+}$ & $6: 10: 5$ & $4: 5: 5$ & - \\
\hline \multicolumn{4}{|l|}{ Number of subjects who underwent each test } \\
\hline Pulmonary function & 20 & 13 & 7 \\
\hline Bronchial responsiveness & 19 & 14 & 7 \\
\hline Blood eosinophils & 21 & 14 & 7 \\
\hline Serum ECP & 18 & 12 & 7 \\
\hline BAL & 20 & 13 & 7 \\
\hline Bronchial biopsy & 21 & 13 & 7 \\
\hline
\end{tabular}

*: normal range: $<138 \mathrm{U} \cdot \mathrm{mL}^{-1} ;{ }^{\dagger}:$ as determined by positive serum immunoglobulin $(\mathrm{Ig}) \mathrm{E}$ antibody to at least one common inhalant allergen; $\ddagger$ inhaled $\beta_{2}$-agonists; $\$$ : oral sustained-release theophyllines; \#: inhaled beclomethasone dipropionate; +: see text for definition. ECP: eosinophil cationic protein; BAL: bronchoalveolar lavage. 
of upper and lower airways was achieved with $2 \%$ lidocaine, and an Olympus Type 20 bronchoscope (Olympus, Tokyo, Japan) was subsequently introduced through the mouth.

BAL was performed at one of the subsegmental bronchi of the right middle lobe. Four $50 \mathrm{~mL}$ aliquots of sterile saline $(200 \mathrm{~mL}$ total) were instilled and collected by gentle syringe suction. Lavage fluid specimens were centrifuged at $125 \times \mathrm{g}$ to pellet cells, and the supernatant was removed. The cell pellets were washed once in phosphate-buffered saline, and cells were counted with a haemocytometer. Differential cell counts were determined on centrifuged preparations stained with May-Grünwald-Giemsa. A minimum of 500 cells were counted with standard morphological criteria used for classifying cells as macrophages, lymphocytes, eosinophils, neutrophils, or epithelial cells.

After the lavage, three mucosal biopsies were obtained from the carinae of the basal segments of the right lower lobe using FB-19C forceps (Olympus). The biopsy specimens were embedded in paraffin wax and were cut into $4 \mu \mathrm{m}$ sections for staining with haematoxylin and eosin. The number of eosinophils in the lamina propria was counted in each specimen using an eyepiece graticule. The result was expressed as the total of the three specimens $\left(\mathrm{n} \cdot \mathrm{mm}^{-2}\right.$ of lamina propria). Examination of BAL fluid and bronchial tissue inflammatory cells was performed in a blind fashion.

All the subjects tolerated the procedure well, and no serious complications were observed in any subject.

\section{Clinical severity}

Clinical severity of classic asthma was classified according to the International Consensus Report on Diagnosis and Treatment of Asthma [17];

score of 1 (mild): intermittent, brief symptoms $<1-2$ times a week; nocturnal symptoms $<2$ times a month; asymptomatic between exacerbations;

score of 2 (moderate): exacerbations $>1-2$ times a week; nocturnal symptoms $>2$ times a month; symptoms requiring inhaled $\beta_{2}$-agonist almost daily;

score of 3 (severe): frequent exacerbations; continuous symptoms; frequent nocturnal symptoms; physical activities limited by the disease.

Clinical severity of CVA was classified according to an original scoring system, because no validated severity scores of CVA have been reported. The system takes account not only of the frequency of the symptom, i.e., cough, but of medication required to achieve control, as recommended by CocксRоғт and Swystun [18] in a recent report on the classification of asthma severity:

score of 1: Coughing is intermittent (not daily), which can be controlled with an as needed use of an inhaled $\beta_{2}$-agonist alone;

score of 2: Coughing occurs daily, which can be controlled with a sustained-release theophylline taken twice daily and an inhaled $\beta_{2}$-agonist used as needed;

score of 3: Coughing occurs daily, which can be partially suppressed but cannot be controlled with a sustainedrelease theophylline taken twice daily and an inhaled $\beta_{2^{-}}$ agonist used as needed.

In the patients with classic asthma or CVA taking a sustained-release theophylline, the serum concentration of theophylline had been monitored and maintained in the therapeutic range $\left(10-15 \mu \mathrm{g} \cdot \mathrm{mL}^{-1}\right)$. Some of the patients with classic asthma or CVA classified with a score of 3 had additionally been treated with inhaled beclomethasone.

\section{Bronchial responsiveness and pulmonary function}

Bronchial responsiveness and pulmonary function were tested on the afternoon of separate days within one week prior to blood sampling and bronchoscopy.

Bronchial responsiveness was examined by a continuous methacholine inhalation method with simultaneous measurement of respiratory resistance $\left(R \mathrm{rs} ; \mathrm{cm} \mathrm{H}_{2} \mathrm{O} \cdot \mathrm{L}^{-1} \cdot \mathrm{s}^{-1}\right)$, using a device developed by TAKISHIMA et al. [19] (Astograph; Chest, Tokyo, Japan). Briefly, twofold increasing concentrations of methacholine chloride (Daiichi Kagaku Yakuhin Co., Tokyo, Japan) diluted in physiological saline (in 10 dose steps from $49 \mu \mathrm{g} \cdot \mathrm{mL}^{-1}$ to $25 \mathrm{mg} \cdot \mathrm{mL}^{-1}$ ) were inhaled during tidal breathing from Bird nebulizers (Bird Corp., Palm Springs, CA, USA) with an output of 0.15 $\mathrm{mL} \cdot \mathrm{min}^{-1}$. After recording the baseline $R \mathrm{rs}$ for $1 \mathrm{~min}$, methacholine was inhaled sequentially at 1 min intervals, until the $R$ rs reached approximately twice the baseline value or until the maximum concentration had been administered. The cumulative dose of inhaled methacholine at the inflection point at which $R$ rs begins to increase ( $D$ min), was adopted as the marker for bronchial responsiveness [19, 20]. This parameter was measured in terms of a unit defined as $1 \mathrm{~min}$ inhalation of $1 \mathrm{mg} \cdot \mathrm{mL}^{-1}$ methacholine. The total cumulative dose of methacholine at the end of inhaling the highest dose $\left(25 \mathrm{mg} \cdot \mathrm{mL}^{-1}\right)$ was 50 units.

This method has been used as a clinical test for bronchial responsiveness $[20,21] . D$ min is reported to have a strong positive correlation $(\mathrm{r}=0.94)$ with the cumulative dose of methacholine required to reduce specific airway conductance by $35 \%$ of the baseline value (PD35,sGaw) [21] obtained by a standard, intermittent inhalation method.

Spirometric tests were performed with a Chestac-65V (Chest, Tokyo, Japan).

\section{Statistical analysis}

Data are expressed as median values with ranges in parentheses. To analyse differences between individual groups, the Mann-Whitney U test was performed. For multiple comparisons, Bonferroni's correction was used. To assess the relationship between clinical severity and indices of eosinophilic inflammation, Spearman's rank-correlation test was performed.

\section{Results}

\section{Clinical findings}

The background of the studied subjects is presented in table 1 . The three groups were similar in age and sex. The duration of the disease and total immunoglobulin $\mathrm{E}$ ( IgE) titre were not significantly different between classic asthma and CVA. Fifteen of the classic asthma cases and six of the CVA cases were atopic; the prevalence of atopy was not different between the two asthmatic groups by the Chi-square test. The medications used before entry into the study, the clinical severity of the disease, and the number of subjects who underwent each examination for each group were as shown in table 1 . 


\section{Pulmonary function and bronchial responsiveness}

The outcomes of the three groups are presented in table 2. FEV1 (\% predicted) and maximum expiratory flow at $25 \%$ of forced vital capacity (MEF $25 \% \mathrm{FVC})$ ) (\% pred) were significantly lower in classic asthma and CVA when compared with the control group. Mean forced mid-expiratory flow (FEF25-75\%) (\% pred) was significantly lower for the classic asthmatics when compared with the controls, but not for the CVA cases.

At methacholine challenge, $R$ rs did not increase at all in the control subjects, even when the highest concentration of methacholine had been exhausted. Their $D$ min value was estimated at 50 units for convenience. Dmin was significantly lower in classic asthma and CVA when compared with the control.

No significant difference was found between classic asthma and CVA for the indices of pulmonary function or bronchial responsiveness.
Blood eosinophils, serum ECP, and BAL fluid and tissue eosinophils

The serum ECP level was significantly increased for classic asthma and for CVA when compared with the control (table 2 and fig. 1a). There was a trend toward a higher number of blood eosinophils in the two asthmatic groups compared with the control, but the difference failed to reach significance (table 2).

The total cell number or percentages of macrophages, lymphocytes, neutrophils, or epithelial cells in BAL fluid were not significantly different among the three groups (table 2). The percentage of eosinophils in BAL fluid and the number of eosinophils in bronchial tissue were significantly increased for classic asthma and CVA when compared with the control (table 2 and fig. $1 \mathrm{~b}$ and c).

No significant difference was found between classic asthma and CVA for blood eosinophil number, serum ECP level, or percentage or number of eosinophils in BAL fluid

Table 2. - Outcomes in the three groups

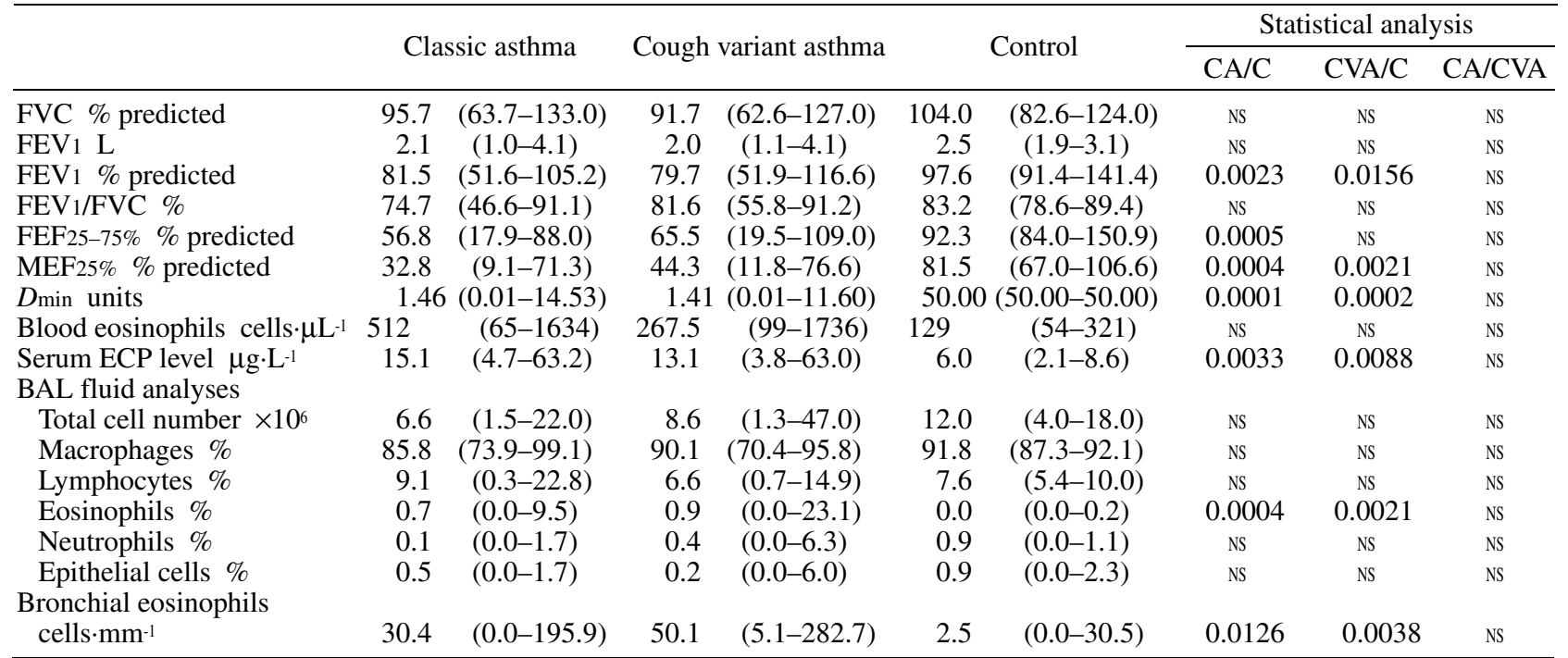

FEF25-75\%: mean forced expiratory flow during the middle half of the FVC; MEF25\%: maximum forced expiratory flow at 25\% FVC; $D$ min: dose of methacholine as a measure of bronchial responsiveness (see text for detail); CA: classic asthma; C: control; CVA: cough variant asthma; FVC: forced vital capacity; FEV1: forced expiratory volume in one second; BAL: bronchoalveolar lavage; ECP: eosinophil cationic protein; Ns: nonsignificant.
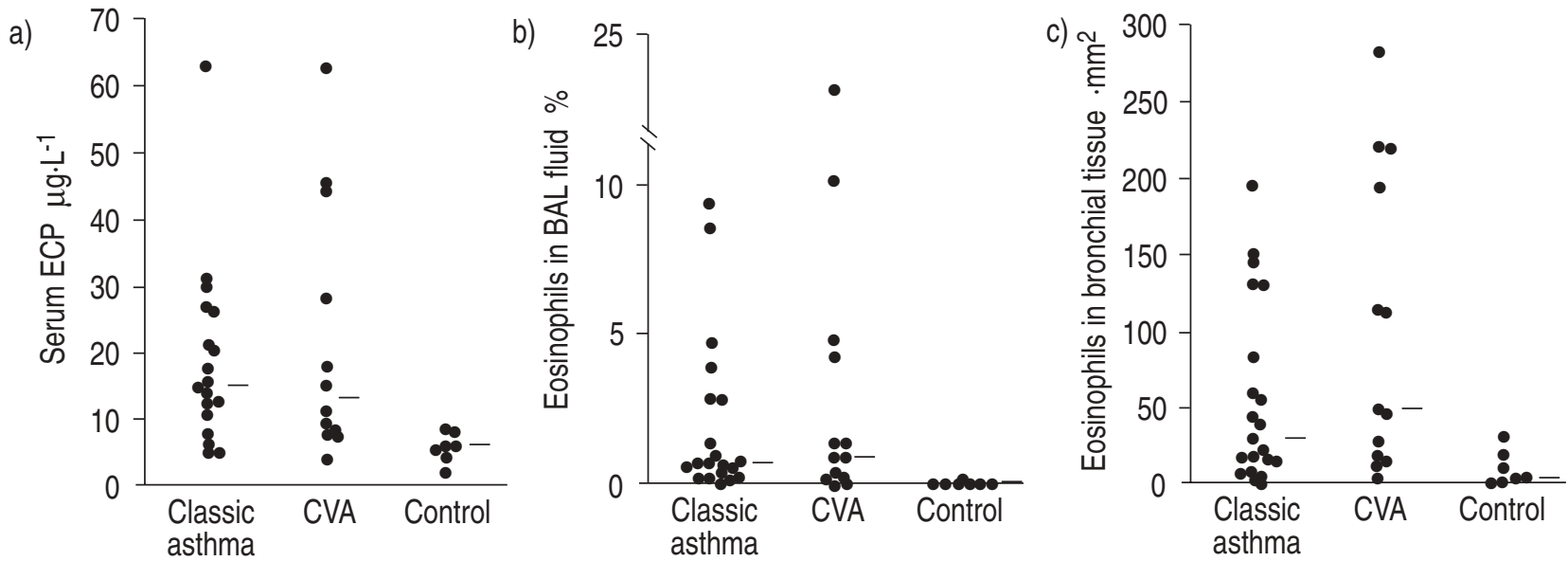

Fig. 1. - Serum eosinophil cationic protein (ECP) level a), percentage of eosinophils in bronchoalveolar lavage (BAL) fluid b), and number of eosinophils in bronchial tissue c) in the three groups. For each index, a significant increase was seen in both classic asthma and cough variant asthma (CVA) when compared with the control. No difference was found between the two asthmatic groups. Bars represent the median values. See table 2 for $\mathrm{p}$-values. 


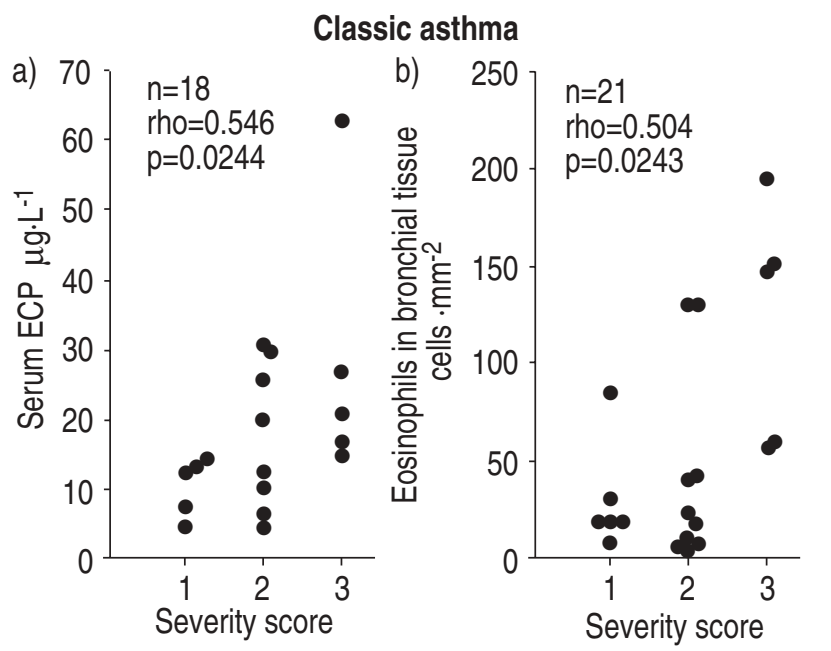

Cough variant asthma

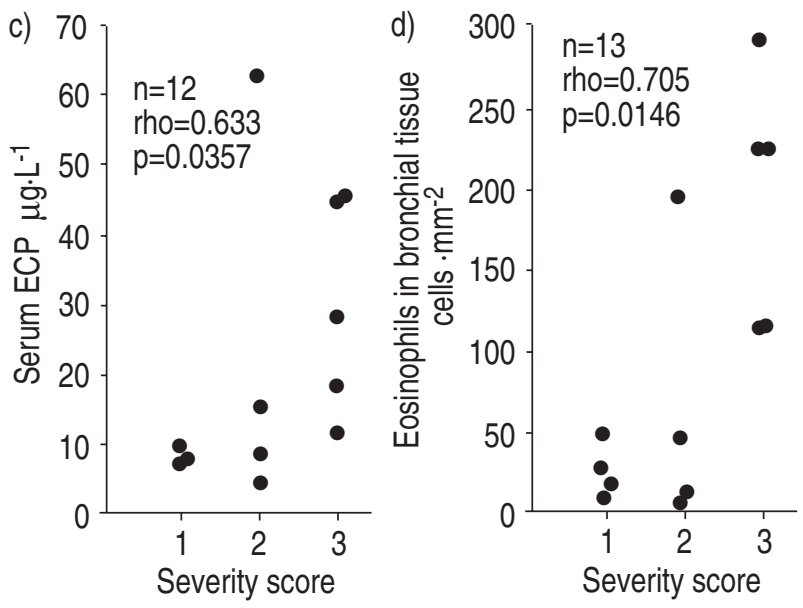

Fig. 2. - Relationship of the severity scores with the serum eosinophil cationic protein (ECP) level and number of eosinophils in bronchial tissue in classic asthma (a, b) and in cough variant asthma (c, d). Significant correlations of the severity score with the serum ECP level and the tissue eosinophil number were found in both groups.

or bronchial tissue (table 2). A comparison between atopic and nonatopic subjects from the classic asthma group, or CVA group, also failed to reveal a significant difference for these indices of eosinophilic inflammation (data not shown).

\section{Correlation between clinical severity and intensity of eosinophilic inflammation}

For both classic asthma and CVA, the clinical severity significantly correlated with serum ECP level and tissue eosinophil number (fig. 2). The clinical severity did not correlate with blood eosinophil number or BAL eosinophil percentage in both conditions.

\section{Discussion}

The present study shows that: 1) the percentage or number of eosinophils in BAL fluid and bronchial tissue and serum ECP level are significantly increased in patients with CVA and classic asthma when compared with the controls; and 2) the serum ECP level and tissue eosinophil number significantly correlate with clinical severity in both conditions. These results indicate the involvement of eosinophilic inflammation in CVA, as well as confirm the results of previous studies on the relationship between eosinophils and classic asthma.

How inflammation correlates to cough in CVA is not clear. Several review articles $[5,22,23]$ speculate on this issue. O'Connell et al. [5] have hypothesized that patients with CVA might have inflammation solely in the large airways, where cough receptors are abundant. WooLcock [22] has also stated that cough receptors are assumedly stimulated by the inflammatory process, and that cough in CVA will be mediated in the central airways. Here we performed bronchial biopsy at segmental bronchi, relatively central airways, and BAL, which might reflect the inflammation of the whole airways from subsegmental bronchi to alveoli. Both procedures, however, revealed no differences between classic asthma and CVA. The site of inflammation may not be causally related to the difference in presenting manifestations from these results. Examinations at more central airways (e.g., biopsy at lobar bronchi or carinae, or brushing cytology at trachea) are required in a future study to elucidate this issue. Participation of tussive mediators such as prostaglandin $\mathrm{E}_{2}$ and a neuropeptide substance $\mathrm{P}$, which are secreted from eosinophils [10], may also be a possible mechanism [5, 23].

GiBSon et al. [24, 25] have reported on several patients with chronic cough with normal pulmonary function tests and normal bronchial responsiveness. These patients showed an increase in eosinophils as well as metachromatic cells in sputum, as with classic asthmatic patients. After treatment with an inhaled corticosteroid, cough decreased markedly. In addition, bronchial responsiveness improved in the "normal" range for some patients. The authors labelled these patients as "eosinophilic bronchitis without asthma". The presence of bronchial responsiveness in CVA but not in eosinophilic bronchitis in the studies by GIBSON et al. $[24,25]$ is difficult to explain, since eosinophilic inflammation, an essential cause of bronchial responsiveness in asthma [10-12], is present in both conditions. It may be due to the possible difference in the two groups in: 1) the intensity of inflammation (number of infiltrating eosinophils); 2) the degree of activation but not just the number of eosinophils; 3 ) the initial level of bronchial responsiveness at the onset of inflammation; or 4) the location of inflammation [24, 25]. Since inflammatory cell composition was examined in these studies in sputum, and not in BAL or bronchial tissue, the source of eosinophils is not clear and might possibly be different from that of CVA.

The mechanism of cough in asthma has also been discussed in view of airflow obstruction. SALEM and AvIADO [26] proposed that cough receptors are stimulated by loc-al bronchoconstriction. As bronchodilators are effective against cough in CVA, this may be a possible pathogenetic mechanism [9]. MCFADDEN [27] described a group of asthmatics for whom cough was the predominant symptom at exacerbation. Pulmonary function tests revealed narrowing of the central airways, whereas another group of asthmatics, who predominantly complained of dyspnoea, had narrowing of the peripheral airways. He attributed the predominance of cough in the former group to central airways obstruction. Other studies of CVA, however, showed almost normal pulmonary function [1-3] or peripheral rather than central airways obstruction [7] at baseline. Examinations after methacholine challenge [1] or exercise [2] re- 
vealed obstruction of both central and peripheral airways, as seen identically in classic asthmatics [1], or obstruction predominantly in the peripheral airways [2]. In the present study, the parameters of baseline pulmonary function, including indices of both central and peripheral airways obstruction, and bronchial responsiveness, did not significantly differ between classic asthma and CVA patients. It is thus not certain whether the site of airflow obstruction or degree of bronchial responsiveness [8] is causally related to the difference in presenting manifestations. One possible mechanism for cough without wheeze in CVA is proposed by $\mathrm{K}$ он et al. [8]; they demonstrated a higher wheezing threshold to inhaled methacholine in CVA than in classic asthma. Heightened cough receptor sensitivity may also be a mechanism [23], but some reports negate this possibility [9] and the issue is still controversial.

There is much evidence that the prevalence of asthma is increasing worldwide. However, the disease, is still underdiagnosed [28]. Recognition of CVA in the differential diagnosis of patients with chronic cough is quite important from a clinical standpoint [1,3-5], although its pathogenetic mechanisms have not yet been fully elucidated. Appropriate diagnostic procedures, including a bronchial responsiveness test, should be considered. The presence of blood and/or sputum eosinophilia, which may suggest the presence of eosinophilic airway inflammation and possible diagnosis of CVA, may be of some help in the initial assessment of patients with chronic cough.

Undertreatment of asthma may result not only in poor control of symptoms but in irreversible pathological changes of the airways, which is assumed to be due to persistent inflammation [29]. Such irreversible changes may occur also in cough variant asthma, since inflammation is present in the airways of patients with cough variant asthma, as demonstrated in this study. Early introduction of inhaled corticosteroids may lead to better prognosis in cough variant asthma, as reported for classic asthma [30]. This issue should be investigated in future studies.

Acknowledgements: The authors thank M. Kurozumi, T. Homma, K. Kataoka and T. Ueda for their assistance.

\section{References}

1. Corrao WM, Braman SS, Irwin RS. Chronic cough as the sole presenting manifestation of bronchial asthma. $N$ Engl J Med 1979; 300: 633-637.

2. Cloutier MM, Loughlin GM. Chronic cough in children: a manifestation of airway hyperreactivity. Pediatrics 1981; 67: 6-12.

3. Hannaway PJ, Hopper GDK. Cough variant asthma in children. JAMA 1982; 247: 206-208.

4. Irwin RS, Curley FJ, French CL. Chronic cough. The spectrum and frequency of causes, key components of the diagnostic evaluation, and outcome of specific therapy. Am Rev Respir Dis 1990; 141: 640-647.

5. O'Connell EJ, Rojas AR, Sachs MI. Cough-type asthma: a review. Ann Allergy 1991; 66: 278-285.

6. Niimi A, Amitani R, Kawai M, Nishiyama H, Maekawa $\mathrm{N}$, Kuze F. Sputum eosinophilia in cough variant asthma (abstract). Am Rev Respir Dis 1991; 143 (Suppl.): A30.

7. Niimi A, Amitani R, Matsui Y, et al. Clinical study on cough variant asthma. Jpn J Thorac Dis 1992; 30: 10771084.

8. Koh YY, Chae SA, Min KU. Cough variant asthma is associated with a higher wheezing threshold than classic asthma. Clin Exp Allergy 1993; 23: 696-701.

9. Fujimura M, Kamio Y, Hashimoto T, Matsuda T. Cough receptor sensitivity and bronchial responsiveness in patients with only chronic nonproductive cough: in view of effect of bronchodilator therapy. J Asthma 1994; 31: 463-472.

10. Bjornsdottir US, Quan SF, Busse WW. Eosinophils and asthma. In: Busse WW, Holgate ST, ed. Asthma and rhinitis. Boston, Blackwell Scientific Publications, 1995: pp. 328-346.

11. Wardlaw AJ, Dunnette S, Gleich GJ, Collins JV, Kay AB. Eosinophils and mast cells in bronchoalveolar lavage in subjects with mild asthma. Am Rev Respir Dis 1988; 137: 62-69.

12. Kirby JG, Hargreave FE, Gleich GJ, O'Byrne PM. Bronchoalveolar cell profiles of asthmatic and nonasthmatic subjects. Am Rev Respir Dis 1987; 136: 379-383.

13. Gibson PG, Girgis-Gabardo A, Morris MM, et al. Cellular characteristics of sputum from patients with asthma and chronic bronchitis. Thorax 1989; 44: 693-699.

14. Bousquet J, Chanez P, Lacoste JY, et al. Eosinophilic inflammation in asthma. N Engl J Med 1990; 323: 1033-1039.

15. Carney IK, Gibson PG, Murree-Allen K, Saltos N, Olson LG, Hensley MJ. A systemic evaluation of mechanisms in chronic cough. Am J Respir Crit Care Med 1997; 156: 211-216.

16. Venge P. Serum measurements of eosinophil cationic protein (ECP) in bronchial asthma. Clin Exp Allergy 1993; 23 (Suppl. 2): 3-7.

17. National Heart, Lung and Blood Institute, National Institutes of Health. International consensus report on diagnosis and treatment of asthma. Eur Respir J 1992; 5: 601-641.

18. Cockcroft DW, Swystun VA. Asthma control versus asthma severity. J Allergy Clin Immunol 1996; 98: 1016-1018.

19. Takishima T, Hida W, Sasaki H, Suzuki S, Sasaki T. Direct-writing recorder of the dose-response curves of the airway to methacholine. Chest 1981; 80: 600-606.

20. Mochizuki H, Shigeta M, Kato M, Maeda S, Shimizu T, Morikawa A. Age-related changes in bronchial hyperreactivity to methacholine in asthmatic children. Am J Respir Crit Care Med 1995; 152: 906-910.

21. Ishii M, Hida W, Suzuki S, Ichinose M, Sasaki H, Takishima T. Comparison of intermittent and continuous inhalation provocation tests. Ann Allergy 1989; 62: 223-228.

22. Woolcock AJ. How does inflammation cause symptoms? Am J Respir Crit Care Med 1996; 153: S21-S22.

23. Lalloo UG, Barnes PJ, Chung KF. Pathophysiology and clinical presentations of cough. J Allergy Clin Immunol 1996; 98: S91-97.

24. Gibson PG, Dolovich J, Denburg J, Ramsdale EH, Hargreave FE. Chronic cough: eosinophilic bronchitis without asthma. Lancet 1989; 1: 1346-1348.

25. Gibson PG, Hargreave FE, Girgis-Gabardo A, Morris M, Denburg JA, Dolovich J. Chronic cough with eosinophilic bronchitis: examination for variable airflow obstruction and response to corticosteroid. Clin Exp Allergy 1995; 25: 127-132.

26. Salem H, Aviado DM. Antitussive drugs. Am J Med Sci 1964; 247: 585-600.

27. McFadden ER Jr. Exertional dyspnea and cough as preludes to acute attacks of bronchial asthma. $N$ Engl J Med 1975; 292: 555-559.

28. Burney PGJ. Current questions in the epidemiology of asthma. In: Holgate ST, ed. Asthma: Physiology, Immunopharmacology, and Treatment. London, Academic Press; 1993: pp. 3-25.

29. Bousquet J, Chanez P, Lacoste JY, et al. Asthma: a disease remodeling the airways. Allergy 1992; 47: 3-11.

30. Selroos O, Pietinalho A, Lofroos A-B, Riska H. Effect of early $v s$ late intervention with inhaled corticosteroids in asthma. Chest 1995; 108: 1228-1234. 